\title{
A utilização do jogo Angry Birds Space na aprendizagem de conceitos de lançamento de projéteis e de gravidade no ensino fundamental: uma proposta de unidade de ensino potencialmente significativa
}

Savana dos Anjos Freitas*, Agostinho Serrano de Andrade Neto**

\section{Resumo}

O ensino de física no ensino fundamental tem estado praticamente esquecido em nosso país, tanto na pesquisa em ensino como na prática em sala de aula. Nossa estrutura curricular considera o ensino específico de física apenas a partir do ensino médio. Neste trabalho, mostramos como utilizar o jogo Angry Birds Space para uma aprendizagem significativa dos conceitos de lançamento de projéteis e de gravidade no ensino fundamental. O produto educacional explanado foi baseado em um subprojeto do Programa Institucional de Bolsas de Iniciação à Docência de Física da Universidade Luterana do Brasil e, com algumas modificações, foi montado na sequência didática de unidade de ensino potencialmente significativa. É possível utilizar essa sequência em um contexto educacional e abordar conceitos simples de física no ensino fundamental.

Palavras-chave: Angry Birds Space. Ensino de física. Ensino fundamental. Lançamento de projéteis. Unidade de ensino potencialmente significativa.

\section{Introdução}

$\mathrm{O}$ presente artigo tem como incumbência descrever um produto educacional com o uso do jogo Angry Birds Space para a aprendizagem dos conceitos de lançamento de projéteis e de força da gravidade. Esse produto foi baseado em um projeto realizado em 2014, por meio

\footnotetext{
Mestranda de Ensino de Ciências e Matemática na Universidade Luterana do Brasil, Canoas, RS. E-mail: savanafreitas_@hotmail.com

** Professor adjunto do Programa de Pós-Graduação em Ensino de Ciências e Matemática e do curso de licenciatura em Física da Universidade Luterana do Brasil, Canoas, RS. E-mail: asandraden@gmail.com
} 
do Programa Institucional de Bolsa de Iniciação à Docência (Pibid) do curso de Física da Universidade Luterana do Brasil situada na cidade de Canoas, RS.

Sabe-se que o lançamento de projéteis é um assunto de grande importância histórica e atual, desde as catapultas utilizadas nas guerras dácias entre o império romano e a Dácia (101 d.C. - 102 d.C. e 105 d.C. - 106 d.C.) até a Primeira Guerra Mundial. Pode-se observar o uso de lançamento de projéteis no lançamento de foguetes, em modalidades esportivas, em que diferentes objetos são arremessados e, também, na caça, muito comum entre os povos indígenas. Assim, desde a antiguidade clássica, muitos filósofos tentaram explicar como ocorria o lançamento de projéteis (FREITAS; SERRANO; SILVA, 2016).

O primeiro foi Aristóteles (NEVES, 2000), que argumentava que, depois da perda de contato com o projetor - que poderia ser um estilingue ou catapulta -, a continuação do movimento era explicada da seguinte maneira: quando se movimenta, o projétil passa a ocupar o lugar que antes era preenchido pelo ar que havia a sua frente. A explicação de Hiparco (PEDUZZI, S.; PEDUZZI, L., 1988) difere da aristotélica, pois, para ele, existe uma força que é transmitida e fica armazenada no projétil (força impressa) quando é arremessado; com o passar do tempo, essa força interna vai diminuindo. Por mais que esses dois filósofos gregos discordem de como ocorre o lançamento de projéteis, ambos descreveram o movimento de um projétil em uma trajetória retilínea.

O filósofo francês Jean Buridan (1300-1358) relatou o ímpeto dado pelo impulsor na velocidade do corpo em movimento, e o que ele imaginou guarda alguma semelhança com o conceito que atualmente chamamos de momentum. Ele defendeu que um projétil adquire um ímpeto, quando arremessado, fazendo, assim, produzir o movimento, o que diminui a intensidade das forças, seria o ímpeto armazenado dentro do projétil (ROONEY, 2013).

Há muito tempo o lançamento de projéteis está presente em nossa sociedade, com isso, há a necessidade de estudar e a possibilidade de relacionar isso com o cotidiano dos estudantes. Essa relação pode ocorrer por meio da utilização de um jogo de celular, despertando interesse e curiosidade nos discentes, por utilizar uma tecnologia que, muitas vezes, é considerada apenas um hobby.

O produto educacional que é apresentado foi fundamentado no subprojeto de física do Pibid realizado na E. M. E. F. João Paulo I - escola pública municipal de um bairro da cidade de Canoas, na qual boa parte dos alunos encontra-se em situação de vulnerabilidade social - e na sequência didática elaborada por Moreira (2011), as unidades de ensino potencialmente significativas (Ueps). 
A Ueps é baseada em teorias de aprendizagem, particularmente na teoria da aprendizagem significativa, partindo das premissas de que não existe ensino sem aprendizagem, o ensino é o meio, e a aprendizagem é o fim.

Tendo isso em vista, este trabalho tem o intuito de contribuir com o ensino dos conceitos de lançamento de projéteis e de força de gravidade a estudantes do ensino fundamental, utilizando uma sequência didática que busca a aprendizagem significativa, bem como o uso de tecnologias, para atrair o interesse dos estudantes pelo ensino de física.

\section{○ uso de tecnologias na sala de aula}

A utilização de tecnologias da informação e comunicação (TICs) está cada dia mais presente no cotidiano da sociedade. Nas salas de aula brasileiras, não é diferente. Segundo Soares e Carmo (2016), tanto nas escolas de ensino fundamental como nas de ensino médio, é incontestável o uso de dispositivos eletrônicos pelos jovens no dia a dia, até mesmo entre aqueles que o nível socioeconômico não é tão propício para isso. A presença de computadores e demais dispositivos digitais é uma realidade atualmente, independentemente da idade. Por meados dos anos 1990, foi constatado que no Brasil houve um crescimento na utilização de TICs, além da presença de computadores nas salas de aula (LOCATELLI; ZOCH; TRENTIN, 2015). Porém, cabe o questionamento: como utilizar, de uma maneira proveitosa e sem prejudicar a educação, a tecnologia na sala de aula, já que está mais acessível a cada dia?

Conforme Rosa, Trentin e Biuzus, a utilização das tecnologias como um

[...] subsídio didático tem sido cada vez mais requisitada por alunos e professores e, aos poucos, vem se consolidando como uma importante e indispensável ferramenta no contexto educacional (2017, p. 25).

Dessa maneira, acreditamos que a utilização das tecnologias pode auxiliar professores e alunos em todo o contexto escolar. Conforme Mendes, Rehfeldt e Neide (2017), é possível haver resultados satisfatórios com o emprego de TICs no ensino, porque as tecnologias podem ser um fomento aos estudantes, despertando neles o interesse pela ciência.

$\mathrm{O}$ uso de TICs pode ter uma influência positiva, quando usadas como suporte ao trabalho docente. Conforme Lamb (2014), o uso do jogo pode ajudar os estudantes a explorarem conceitos matemáticos. Por isso, buscamos evidenciar o provento que um jogo de celular, de fácil acesso por não ser pago e estar disponível em sistema Android, pode trazer aos estudantes do ensino fundamental. O jogo Angry Birds Space é utilizado por professores tanto no Brasil (EXTRA GLOBO, 2014; TERRA 
NOTÍCIAS, 2014; FREITAS; SERRANO; SILVA, 2016) quanto em outros lugares no mundo para o ensino de matemática e física (SCIENTIFIC AMERICAN, 2014).

\section{Teoria da aprendizagem significativa}

A proposta deste trabalho é realizar uma atividade didática com os alunos do ensino fundamental - nível que frequentemente é negligenciado dentro da perspectiva do ensino de física - sobre os conceitos de lançamento de projéteis e de gravidade, por meio do uso de jogos de celulares. $\mathrm{O}$ uso deses jogos pode servir como organizador prévio ausubeliano, à medida que leva os alunos a explicitar os seus subsunçores.

Tendo como base os resultados da situação inicial, o docente necessita introduzir algumas situações-problema, visando a preparar uma abordagem mais concreta de determinados conteúdos a serem trabalhados. E, para exemplificar a devida atividade, utilizamos a série de jogo mundialmente conhecida Angry Birds, mais especificamente um dos últimos lançamentos, o Angry Birds Space. Após essa primeira parte, o professor pode, da maneira que mais achar conveniente, abordar os conteúdos que foram trabalhados, começando por algo mais geral sobre lançamento de projéteis e gravidade, para, depois, poder explorar mais especificamente esses conceitos (AUSUBEL; NOVAK; HANESIAN, 1980).

$\mathrm{O}$ aporte teórico que fundamenta este artigo é naturalmente a aprendizagem significativa, de David Ausubel, que se encontra discutida de forma ampla em diversas publicações de ensino e no livro do autor. Devido a limitações naturais de espaço desta publicação e ao foco do estudo ser a exposição e a discussão do produto educacional, abstemo-nos de explanar o referencial, que é ubiquamente discutido na área.

A teoria da aprendizagem significativa (TAS) surgiu por meio dos estudos do psiquiatra David Ausubel (1918-2008), durante a década de 1960. Ausubel dedicou-se a compreender a psicologia educacional e, com o passar do tempo, teve contribuições de Donald Novak, Donald Bob Gowin e Marco Antônio Moreira, tendo como objetivo explicar de que forma o aluno aprende com significado (RIBEIRO et al., 2018).

Ausubel entende que a aprendizagem significativa é primordialmente cognitivista, sendo um resultado advindo do armazenamento de informações que fica na mente do aluno de maneira organizada. A interação que acontece entre 0 material e a estrutura cognitiva de quem está aprendendo viabiliza uma modificação definitivamente (WOLFF, 2015). 
Unidades de ensino

\section{potencialmente significativas}

Uma Ueps é uma sequência didática fundamentada em teorias de aprendizagem, em especial, na teoria da aprendizagem significava, mencionada anteriormente, de David Ausubel. Tem o objetivo de ajudar a modificar a situação que se encontra muitas vezes o ensino, na base da memorização de conteúdo, causando apenas uma aprendizagem mecânica e não uma aprendizagem significativa (MOREIRA, 2011). Conforme Moreira, o objetivo dessa sequência didática é desenvolver

[...] unidades de ensino potencialmente facilitadoras da aprendizagem significativa de tópicos específicos de conhecimento declarativo e/ou procedimental (2011, p. 2).

A construção da Ueps segue oito aspectos sequenciais (etapas), sendo que podem ser adaptados conforme o docente achar necessário. Primeiramente, deve-se definir o objetivo da sequência didática e, após, seguir as etapas da Ueps. O primeiro passo é determinar o tópico que deve ser desenvolvido, mostrando seus aspectos declarativos e procedimentais, sendo essa etapa chamada situação inicial.

A situação-problema, segunda etapa, é o momento em que se deve criar/propor situações, como, por exemplo, questionário, discussão e mapa conceitual, e proporcionar ao aluno a externalização de seu conhecimento prévio, pois podem ser empregados como organizadores prévios. Na terceira etapa, aprofundamento de conhecimento, o docente desenvolve com seus discentes, utilizando o quadro negro, slides ou algum recurso didático, o conteúdo a ser ensinado. Nessa etapa, o professor deve explanar com maior ênfase o conceito que tem como objetivo a ser ensinado na Ueps, usando os conhecimentos prévios do aluno que puderam ser observados nas etapas anteriores.

A nova situação-problema possibilita aos alunos, por exemplo, uma aula expositiva-dialogada, em que o professor pode utilizar algumas estratégias para propor uma situação-problema, e os alunos sejam capazes de usar seus conhecimentos prévios juntamente com os conhecimentos explanados na etapa anterior em situações que sejam de um nível mais complexo. Moreira (2011) ainda sugere envolver os alunos em atividades que seja possível ocorrer uma interação social, como trabalhos em grupos, tendo o docente que está aplicando a Ueps como um mediador, e não como um transmissor de conhecimentos.

A quinta etapa é voltada para a avaliação tanto do aluno quando da Ueps como um todo. A avaliação somativa individual pode ser feita ao longo da etapa, conforme é realizada, registrando, durante o processo, aspectos que possam ser considerados evidências de que aconteceu uma aprendizagem significativa. Aproximando-se do fim da atividade, na 
sexta etapa, aula expositiva final, pode-se revisar todos os conceitos estudados, conforme o docente achar mais adequado para os alunos.

A sétima e a oitava etapas são, respectivamente, avaliação da aprendizagem da Ueps e avaliação da própria Ueps. Nessas etapas, é avaliado se ocorreu uma aprendizagem significativa. Para que não aconteça uma aprendizagem mecânica, a aprendizagem deve ser progressiva, com domínio do campo conceitual também progressivo, observando não apenas os comportamentos finais, mas também evidências em todo o decorrer da Ueps. Portanto, a Ueps propicia ao aluno uma aprendizagem significativa crítica, não incitando uma memorização de conteúdo, mas estimulando uma busca por questionamentos.

Desempenho dos estudantes não fica restrito a uma prova final e eles podem avaliar sua própria aprendizagem ao longo do período, aumentando sua confiança e possibilitando que procurem outras fontes sobre o assunto, troquem informações e questionem o professor (GRIEBELER, 2012, p. 60).

Dessa forma, acreditamos que o uso de Ueps, uma metodologia considerada de caráter inovador, auxilia os estudantes a terem uma aprendizagem significativa. Schittler (2015), em sua pesquisa de doutorado, afirma que, por mais que não se consigam evidências em si sobre a aprendizagem significativa, as atividades trabalhadas com a Ueps permitiram au- mentar a predisposição dos educandos para aprender física, ou seja, esse método de ensino auxilia os alunos a terem vontade de aprender, que, conforme Ausubel (1980), é essencial para que aconteça uma aprendizagem significativa.

\section{Produto educacional}

A sequência didática proposta no transcorrer deste trabalho é baseada no artigo "Uma proposta para o ensino de estereoquímica cis/trans a partir de uma unidade de ensino potencialmente significativa (UEPS) e do uso de modelagem molecular" (RAMOS; SERRANO, 2015) e no quarto anexo do artigo que define a Ueps: "Proposta de UEPS para ensinar equilíbrio químico" (SERRANO, 2011), em que é exemplificada uma Ueps conduzida ao ensino de equilíbrio químico. O produto educacional na forma de Ueps proposto conta com as etapas a seguir.

Objetivo: ensinar conceitos de física que envolvem o lançamento de projéteis e a gravidade no ensino fundamental com a utilização do jogo Angry Birds Space.

Situação inicial: utilizando os devidos conhecimento prévios, os estudantes são convidados a realizar uma atividade inicial, em que são divididos em grupos e podem jogar livremente. Os conhecimentos prévios dos alunos podem ajudá-los a conduzir da melhor maneira as estratégias, para avançar no decorrer de cada etapa do jogo. 
Figura 1 - Layout do jogo Angry Birds Space

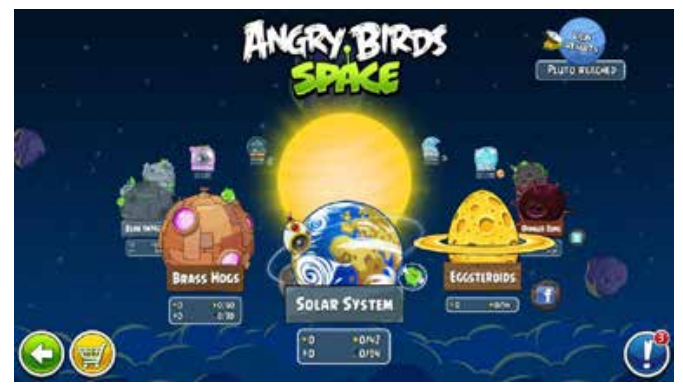

Fonte: pesquisa.

Figura 2 - Nível 1 do jogo Angry Birds Space

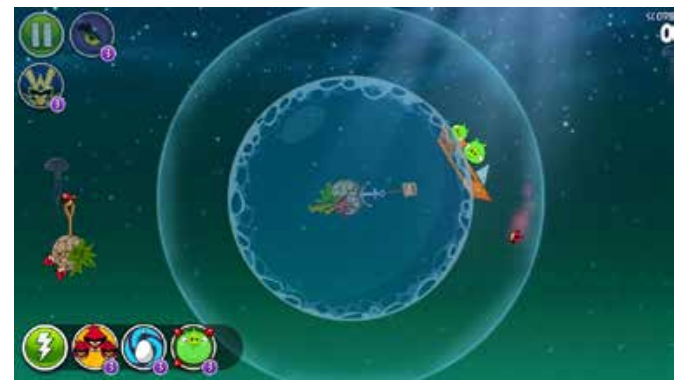

Fonte: pesquisa.

Figura 3 - Alunos jogando Angry Birds Space

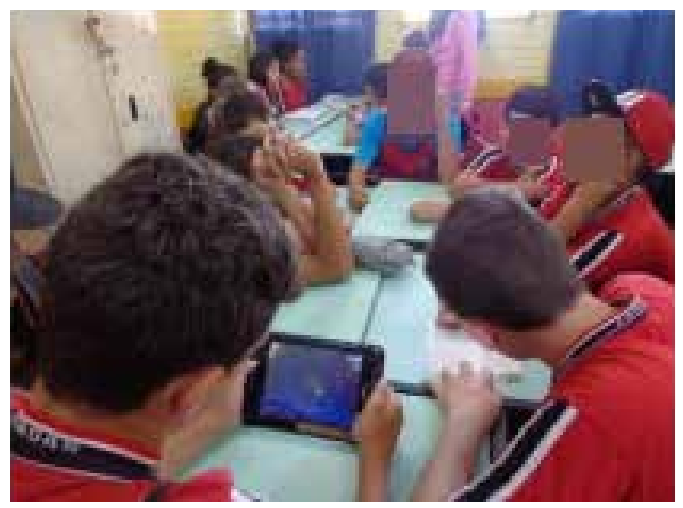

Fonte: Freitas, Serrano e Silva (2016).

$\mathrm{Na}$ primeira etapa, pensada como um organizador prévio, os alunos podem lembrar - sendo estimulados para isso ou não - como se joga com estilingue, uma brincadeira ainda muito comum em alguns bairros e principalmente no interior. É possível que, de forma autônoma, os estudantes relacionem essas brincadeiras com lançamento de projéteis e com o conceito de gravidade, por mais que ainda não tenham tido contato com o conceito físico científico de gravidade.

Situação-problema: depois da primeira atividade proposta, os alunos podem debater nos próprios grupos e, em seguida, com toda a turma. O debate pode ser baseado nas seguintes perguntas, e, quando necessário, pode-se acrescentar informações à questão ou modificá-la, para que o debate faça os estudantes refletirem e exporem seu pensamento em relação à física do jogo.

- A gravidade (bolha em torno do planeta, conforme representado no jogo) influencia quando você joga o pássaro?

- O quanto se estica o estilingue muda a trajetória do pássaro?

- Os diversos pássaros que existem influenciam o acerto de mais ou de menos porcos verdes?

- O que muda com a velocidade do pássaro?

- O que faz a gravidade no jogo?

\section{Aprofundando conhecimentos:} em uma aula, o professor pode utilizar o quadro-negro ou o data-show para explicar os tipos de lançamentos que existem e o conceito de ângulo, fazendo 
relação com o cotidiano dos alunos. Essa etapa deve ser elaborada após a situação-problema, preparando uma aula com base na atividade anterior proposta, em que ocorreram os debates em pequenos grupos e com a turma toda.

Nova situação-problema: em uma aula expositiva-dialogada, o docente pode trabalhar com os alunos utilizando brincadeiras que envolvam lançamentos e gravidade. Por meio de atividades físicas, é possível obter maior participação dos alunos com o projeto em andamento. Como este produto educacional é direcionado a ensinar física para crianças, as atividades físicas se tornam brincadeiras para eles, aumentando o interesse e o entusiasmo, abordando os conceitos principais de uma maneira diferente da que foi proposta na situação-problema anterior.

Uma atividade que pode ser realizada é o vôlei de toalha, em que se trabalha em duplas e em grupos ao mesmo tempo, propiciando a eles a utilização do conhecimento de lançamento oblíquo. Com um balão cheio d'água, os alunos devem jogá-lo para outra dupla, usando uma toalha de banho (Figura 4). Pode-se realizar outra brincadeira, por exemplo, em que eles devem responder sobre o conteúdo, caso deixem a bolinha cair nesta atividade (Figura 5).

Por fim, pode-se jogar novamente em grupo o jogo Angry Birds Space e, consequentemente, fazer um debate em que os estudantes explanem: se houve ou não melhor compreensão dos conceitos de lançamento oblíquo e gravidade utilizando o jogo Angry Birds Space e se, com a explicação dos conceitos físicos que se tem no jogo, ocorreram melhor desempenho do jogador e melhor noção dos assuntos discorridos em aula.

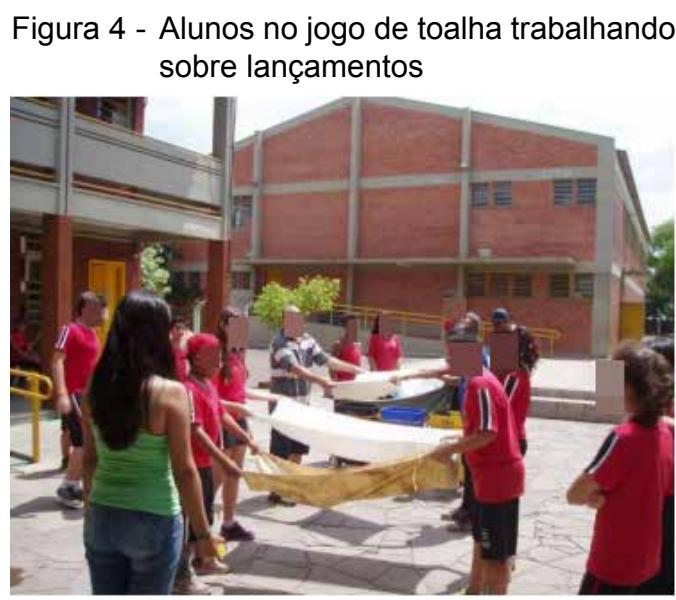

Fonte: Freitas, Serrano e Silva (2016).

Figura 5 - Alunos em atividade de pergunta e resposta

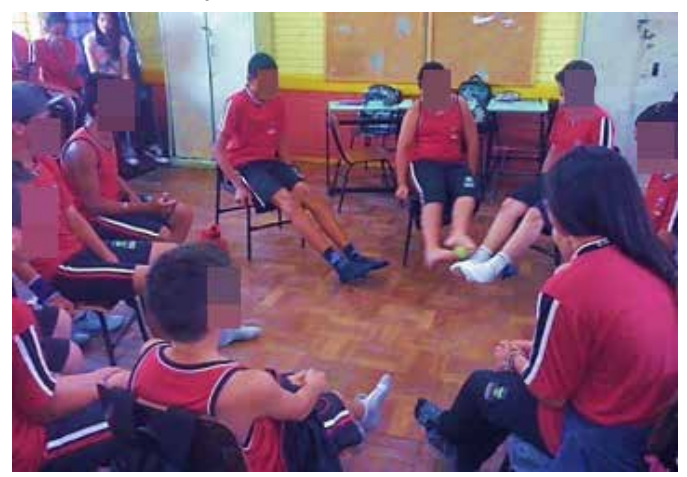

Fonte: Freitas, Serrano e Silva (2016). 
Avaliação somativa individual: depois de se observar todos os debates e atividades realizados, os estudantes podem responder individualmente três questões sobre lançamentos e gravidade. Como são alunos pré-adolescentes, sugere-se que sejam questões que possam ser respondidas por meio de desenho ou de breves textos. A primeira questão pode estar relacionada com o estilingue. A segunda, com bolas de diversos tamanhos: pode-se pedir a eles que desenhem a trajetória que elas irão percorrer. Por fim, deve-se responder a seguinte pergunta: o que é gravidade para você? Nas figuras a seguir, pode-se ver os resultados do trabalho de um aluno que realizou esta avaliação após ter sido aplicada a Ueps.

Figura 6 - Avaliação somativa individual de um aluno

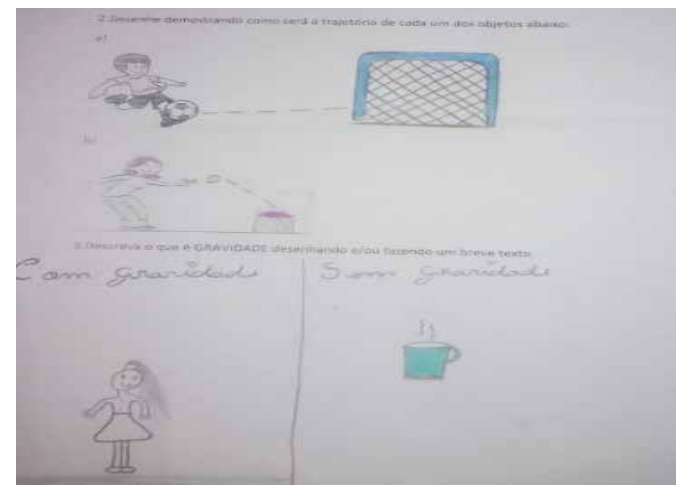

Fonte: Freitas, Serrano e Silva (2016).
Figura 7 - Avaliação somativa individual de um aluno

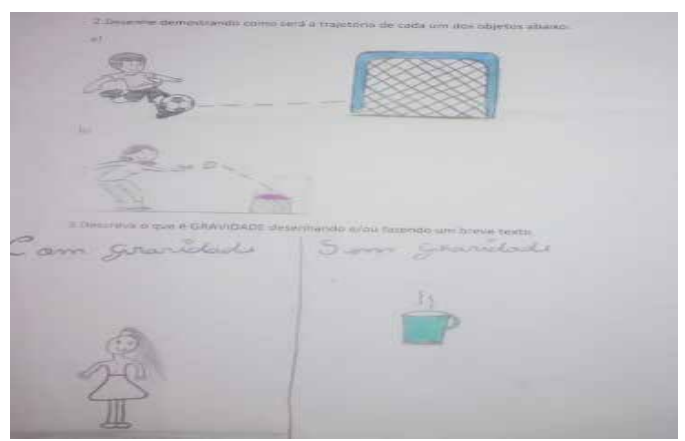

Fonte: Freitas, Serrano e Silva (2016).

Aula integradora final: para encerrar a sequência didática, pode-se revisar todos os conceitos estudados, aplicando-os para explanar a movimentação do pássaro nos diversos cenários do jogo e das atividades realizadas. Em grupo ou no grande grupo, pode-se rever as atividades e estratégias desenvolvidas durante a realização da proposta. Logo, pode-se ressaltar a importância de associar o cotidiano com os conceitos físicos, pois, assim, pode haver melhor aprendizagem significativa.

\section{Avaliação da aprendizagem na}

Ueps: o docente pode registrar proeminências de aprendizagem significativa por intermédio da aquisição e do domínio da ideia que os alunos, individualmente, passaram a ter dos conceitos explanados. É sempre importante lembra que, por ser uma turma de ensino fundamental, os estudantes não tiveram aulas de física sobre o assunto. Posteriormente, caso o professor constate que a aquisição des- 
se conhecimento tornou o aprendizado sobre essa parte da cinemática mais prazerosa para os estudantes, pode-se concluir a efetividade da Ueps.

Avaliação da Ueps: a Ueps sobre o uso do jogo Angry Birds Space só pode ser considerada exitosa se existirem um domínio progressivo dos conceitos de lançamento de projéteis e gravidade, por meio dessa proposta de sequência didática para o ensino fundamental, bem como uma compreensão de que o uso de jogos pode ser uma forma instigadora de se aprender conceitos físicos.

\section{Considerações finais}

Atualmente, são visíveis, entre crianças e jovens, o interesse e a desenvoltura em jogos eletrônicos. Consideramos que, por esse meio, se deve estudar propostas para utilizar esses tipos de jogos em sala de aula, aumentando, assim, o interesse e a curiosidade dos alunos pelas atividades que podem vir a ser propostas em conjunto com essas ferramentas. O Angry Birds Space é um jogo bastante conhecido e simples na sua maneira de jogar. Ele propicia a associação dos movimentos que existem no jogo com o cotidiano e com brincadeiras realizadas pelos estudantes com os mesmos movimentos.

Por meio deste produto educacional, que teve como base o projeto Angry Birds Space, do subprojeto do Pibid de física, e já foi realizado e aplicando na forma de sequência didática de Ueps, confiamos que o jogo pode ser utilizado como uma ferramenta para aprendizagem significava de conceitos sobre lançamento de projéteis e força da gravidade. Por conseguinte, acreditamos que o ensino de física deve efetivamente iniciar já nas séries iniciais, despertando o interesse pela busca científica, para elucidar e estimular a pesquisa e o aprofundamento científico ainda em crianças, não ficando tanto a mercê de suposições vagas e sem fundamentos científicos. Essas mudanças possibilitariam que, durante o ensino médio e, eventualmente, no ensino superior, o aprendizado de leis e conceitos físicos não seja visto como uma experiência negativa.

Trabalhar com jogos eletrônicos e simulações computacionais pode ser a grande chave para despertar a importância da ciência na vida dos alunos. Explorando a curiosidade dos estudantes por meio do jogo, foi possível proporcionar a eles uma visualização melhor dos lançamentos e a explicação da maneira pela qual a força da gravidade age na Terra. Posto isso, sugerimos que mais pesquisas sobre a temática sejam realizadas, contribuindo para o ensino de física no ensino fundamental, e compreendemos que a aplicação deste produto educacional auxilia na formação de docentes e discentes. 
Use of the game Angry Birds Space in the class of concepts of launching projects and recordings in Middle School: a proposal of potentially
meaningful teaching units

\section{Abstract}

The teaching of Physics in Middle School has been practically forgotten in our country, both in research in teaching and in practice in the classroom. The curricular structure present in our country considers the specific teaching of Physics only from High School. In this work, we will show how to use the game Angry Birds Space for a significant learning of launching of projectiles and the concept of gravity in Middle School. The educational product that will be explained in this work was based on the subproject of the PIBID of Physics of the Lutheran University of Brazil and, with some modifications was mounted in the didactic sequence of potentially meaningful teaching units, to be used in a context educational and approach the simple concepts of Physics in Middle School.

Keywords: Angry Birds Space. Physics teaching. Middle school. Launch of projectiles. Potentially meaningful teaching unit.

\section{Referências}

AUSUBEL, D. P.; NOVAK, J. D.; HANESIAN, H. Psicologia educacional. Rio de Janeiro: Interamericana, 1980.

EXTRA GLOBO. Professores utilizam Angry Birds para ensinar física em sala de aula. 2014. Disponível em: <http://extra.globo.com/noticias/ educacao/professores-utilizamangry-birds-pa- ra-ensinar-fisica-em-sala-de-aula-2723541. html>. Acesso em: 31 ago. 2018.

FREITAS, S. A.; SERRANO, A.; SILVA, V. G. Uso de jogos de celular no aprendizado de física no ensino fundamental: um estudo exploratório do uso do jogo Angry Birds Space no ensino do conteúdo de Lançamento de Projéteis. Renote, Porto Alegre, v. 14, n. 1, p. 1-10, 2016.

GRIEBELER, A. Inserção de tópicos de física quântica no ensino médio através de uma unidade de ensino potencialmente significativa. 2012. Dissertação (Mestrado em Ensino de Física) - Universidade Federal do Rio Grande do Sul, Porto Alegre, 2012.

LAMB, H. J. Angry Birds Mathematics: Parabolas and Vectors. MatheMatics teacher. 2014. Disponível em: <http://www.mathematicshed. com/uploads/1/2/5/7/12572836/angry_birds_mathematics_-parabolas__vectors.pdf $>$. Acesso em: 31 ago. 2018.

LOCATELLI, A.; ZOCH, A. N.; TRENTIN, M. A. S. TICs no Ensino de Química: um recorte do "Estado da Arte". Revista Tecnologias na Educação, v. 12, n. 7, p. 1-12, 2015.

MENDES, E. S.; REHFELDT, M. J. H.; NEIDE, I. G. Exploração de simulações como forma de estimular o aprendizado de conceitos da Cinemática Escalar. Revista Brasileira de Ensino de Ciência e Tecnologia, Ponta Grossa, v. 10, n. 2, p. 24-52, maio/ago. 2017.

MOREIRA, M. A. Aprendizagem Significativa: a teoria e textos complementares. São Paulo. Editora Livraria da Física, 2011.

NEVES, M. C. D. Uma investigação ao sobre a natureza do movimento ou sobre uma histioria para a noção do conceito de gorça. Revista Brasileira de Ensino de Física, v. 22, n. 4, 2000.

PEDUZZI, S. S.; PEDUZZI, L. O. Leis de Newton: uma forma de ensiná-las. Caderno Brasileiro de Ensino de Física, v. 5, n. 3, 1988.

RAMOS, A.; SERRANO, A. Estudo da aprendizagem mediada por computador: as contribuições da modelagem molecular para o ensino de química. Renote, v. 12, n. 2, 2014. 
RAMOS, A.; SERRANO, A. Uma proposta para o ensino de estereoquímica cis/trans a partir de uma unidade de ensino potencialmente significativa (UEPS) e do uso de modelagem molecular. Experiências em Ensino de Ciências, v. 10, n. 3, 2015.

RIBEIRO, N. A. et al. Mapas conceituais na compreensão da aprendizagem significativa do conteúdo de probabilidade. Revista de Ensino de Ciências e Matemática, v. 9, n. 2, p. 167-181, 2018.

ROONEY, A. The Story of Phyiscs. Rosen Publishing Group: New York, 2013.

SCHITTLER, D. Laser de rubi: uma abordagem em Unidades de Ensino Potencialmente Significativas (UEPS). 2015. Dissertação (Mestrado em Ensino de Física) - Universidade Federal do Rio Grande do Sul, Porto Alegre, 2015.

SCIENTIFIC AMERICAN. Education Is for the (Angry) Birds. 2014. Recuperado em: 02 jun. 2014. Disponível em: <http://www.scientificamerican.com/article/education-is-for-the-angry-birds>. Acesso em: 02 jun. 2014.

SERRANO, A. Proposta de UEPS para ensinar equilíbrio químico (Anexo 4). Meaningful Learning Review, v. 1, n. 2, p. 43-63, 2011.

SOARES, A.; CARMO, R. Um simulador virtual para o ensino do Movimento Harmônico Simples desenvolvido utilizando o GeoGebra. Revista Brasileira de Ensino de Ciência e Tecnologia, Ponta Grossa, v. 9, n. 3, p. 25-42, maio/ago. 2016.

TERRA NOTÍCIAS. Angry Birds está a caminho das salas de aula brasileiras. 2014. Disponível em: <http://noticias.terra.com.br/ educacao/angry-birds-esta-a-caminho-dassalas-de-aula-brasileiras,e98e78557aa5410 VgnVCM3000009af154d0RCRD.html>. Acesso em: 02 jun. 2014.
WOLFF, J. F. S. Qual a mudança na estrutura cognitiva de estudantes após o uso de simulações computacionais? Uma investigação da relação entre representações computacionais internalizadas e aprendizagem significativa de conceitos no campo das colisões mecânicas em Física. 2015. Tese (Doutorado em Ensino de Ciências e Matemática) - Universidade Luterana do Brasil, Canoas, 2015. 